\title{
CURRICULUM AND SYLLABUS MANAGEMENT - RISK ASSESSMENT OF ALL THE ELEMENTS OF A BUSINESS SYSTEM
}

\author{
Ljiljana Ruzic-Dimitrijevic, Jelena Dakic, Bozo Nikolic, Higher Education Technical School of Professional \\ Studies in Novi Sad, Serbia, ljdimitrijevic@gmail.com
}

\begin{abstract}
The paper presents a specific approach to designing the curriculum and syllabus of a newly formed course for study programmes in information technology, protection and other fields. The topic is risk assessment that is introduced in the course and which is a common element in various fields. The content creation approach is the result of the strong relationship and cooperation between the higher education institution and the overall industrial and nonindustrial sectors of the region.
\end{abstract}

Keywords: curriculum and syllabus, study programme, risk assessment

\section{INTRODUCTION}

The quality of education is vital for the development and progress of each country. Higher education as a crown of this process is of essential importance. Nowadays, limits of education shift and surpass borders of countries, especially in the countries of the European Union that had signed the Bologna Declaration and obliged themselves to mutually coordinate the policy of higher education. In order that the goal is achieved, there are formed accreditation bodies that establish standards for the evaluation and assessment of quality of higher education institutions and study programmes applied there.

Higher education institution sets goals, structure and content of a study programme, fulfilling standards established by the accreditation body and taking care of load of students, results and expertise. Meanwhile, monitoring and control are being carried out and external information collected [1].

Each study programme consists of a number of subjects which are adapted to students `apacities for realizing them during a school year, actually during a semester. Groups of subjects are formed according to types of studies: academic, professional and aristic (this division is applied in Serbia). For examle, professional studies consist of three groups of subjects: general, professional and professionally applicable. Lecturing of these subjects is conducted via classes, audio and laboratory exercises.

Besides, there may also occur a group of subjects with practical content. The structure of the programme is adapted to the outcome and results which are desirable to be realized by the very programme. The share of general, professional and professionally applicable subjects depends on the scientific filed the subject belongs to, and can range from $15 \%$ of general, $40 \%$ of professional and $45 \%$ of professionally applicable subjects. The distribution of these subjects can also be different, depending on the type and degree of higher education. In the Curriculum there is a group of obligatory subjects that define the study programme, as well as a group of elective subjects of free content that have no influence on the character of the study programme.

Some types of studies in Serbia, no matter either we speak of academic or professional ones or of the first or second degree ones, have not been fully identified in the form or their scope, in the fact whether they are consecutive or not, etc. The 21 st century brings some new requirements in the creation of curriculum with the participation of professional bodies for the accreditation of programmes as a professional qualification, consecutiveness and progression. [2]. 


\section{MODELS OF FORMATION THE CONTENT OF THE SUBJECT}

The formation of the subject content depends also on the fact whether the programme is completely newly formed or being updated, or fulfilled by new subjects. Basic model of formation of a subject would be based on a previously formed programme. The programme is formed in such a way that narrowly professional subjects are defined. They should be elaborated by independant experts in the field of programmes, therefore it would be logical that the very programme is unique for a country and even wider. Unfortunately, in Serbia this is not the case and study programmes from the same field in two institutions are frequently very different. Next group of subjects are professional subjects necessary for clear presentation, understanding and application of expertly applied subjects.

What is to be emphasized here is that all the subjects are formed on the basis of the opinion of the professional team of an institution about what a particular subject should contain, in which situation there could also be present personal - subjective attitudes. This part of a programme will be the more quality one, the less is the influence of subjective factors, conducting the integrated concept of the curriculum development. Besides, it is important to constantly monitor and evaluate the quality of the programme [9], [10].

If we exclude the subjective element mentioned in the basic model, in order to obtain a quality plan and programme of a study programme and individual subjects, it is necessary to have a particular number of information at one`s disposal. The information must be collected from the content of previous education, economy, as well as from our environment about the needs and potentials, then also from similar higher school institutions, expert chambers and professional associations. All the information are not possible to be gathered at one place because our higher school institutions usually have no services for collecting them. If the information are collected, there occurs the question to which extent they are real.

The creation of the programme on the basis of previous information could be possible if the individuals from education institutions at the same time are significantly present in economy and other institutions, at the source of information. This is hardly possible in Serbia because the law complicates the realisation of such quality solutions. The only possibility is an incorrect claim of dividing working hours into two institutions which in that kind of solution automatically excludes quality professional staff.

Thesis replacement from this model is significant engagement of teachers in solutions of emerging economy problems. The presence of those problems notably means the need that the topic should be included in study programme as an integral part of a subject.

"The development of experiential, including workplace, learning as part of the university curriculum challenges the role of academics as the constructors and guardians of a specialised form of articulated knowledge, which, as I have argued, is now at least partially mixed with a more tacit kind of knowledge derived not from book learning but from experience..." [2, p. 47].

Nowadays even higher education institutions with acedemic studies recognise the necessity that beside academic knowledge programmes they have to offer students certain employability skills, which will enhance their prospects of employment. [3]

\section{CASE PRESENTATION}

Subject Risk Assesssment and Methods for Risk Assesssment is being conducted over several years within study programme of Occupational health and safety (OHS) in the fourth year. It was designed as a result of the development of profession and application of new rules in this field in Serbia. Certainly, students first had to become familiar with some basic notions of safety and health at work and also aware of the importance of protection at work. That was made possible for them in the subjects of the second and third year: Protection at Work, Regulations in Protection, Business Law, etc. This study programme was positively evaluated on accreditation. Then it only had to be compared to 3 study programmes of the same field and levels, out of which 2 of them had to be from Europe. The method of formation of study programme of this field can be found in the project [12] at Liverpool University created in cooperation with Health and Safety Laboratory which shows how important this cooperation in formation of a quality curriculum is. 


\section{Issues in Information Systems}

Volume 14, Issue x, pp. 463-467, 2013

With the application of regulations in Serbia which required that each company possesses an elaborated document about the assessment of risks at working places and the environment, the teachers of the School in this field started intensively the elaboration of such a document. The School elaborated hundreds of such documents, and since all of them were intended for various companies with different conditions of work and the environment, as well as working places, for each company it was formed a team of teachers of adequate professions. In that way the teachers of the School gained significant experience in the assessment of risks, and professor Nikolić, who initiated and led all the activities, formed a method that by the time underwent modifications in accordance with acquired knowledge and application in various fields of work. Thus a significant number of papers emerged that were related to this topic and applicable also in other fields, like, for example, fire protection and information technologies.

This work of the teachers developed in them consciousness about the importance of risk management in all the fields. In that way, we formed the subject Risk Assessment introduced in all the engineering study programmes of the fourth year. The first part of the subject is common for all and contains general notions of risk management and risk assessment methods. Then the content deals with topics related to risk assessments in the field of study programmes: protection at work, fire protection and rescue, protection of the environment, mechanical engineering, electrical engineering and information technologies.

Shortened subject content [6]:

Theoretical basics of safety: accidents and safety; elements of theory of reliability, human errors. Analysis of safety; procedures, methodological survey. Risk assessment; aims, types of assessment, practical aspects. Types of analyses of safety....

Legal grounds for risk assessment: laws and standards important for a particular field aiming at elaboration of the legislations on risk assessment.

Practical risk assessment: system definition, identification of dangers and harmfulness, risk assessment, principles of risk reduction, documentation of the assessment, measures for reduction, removal and prevention of risks.

The subject Risk Assessment is designed for students to acquire skills for risk assessment in their field, defining all its resources, evaluating their importance for the company, i.e. business system. It is also to be expected an intensive development and application of risk assessment in other elements of business system and its whole [11], [5]. This subject which was introduced to several study programmes that cover wide range of fields enables the formation of an expert team that would be capable of assessment of risk of each part of the business system.

In Serbia there exists a law regulation that is related to assessment of more or less risky drivers in traffic, as well as more or less risky objects from fire and their connection with ensurance system and several other elements. Still, there are no legal obligations to perform risk assessment and rewiev of information systems. However, this study programme is being developed and updated in accordance with technology development and emerging needs. According to special publications published by the American National Institute of Standards and Technology (NIST- 800-50, 16) it is foreseen a model for Training Programme in the field Information Technology Security. It should be consisted of raising awareness - "Security Awareness" of the importance of IT system securuty, adopting basic notions of IT system securuty, acquiring skills for participation in securuty process, as well as education and experience level that forseens the development of conducting complex activities relating to IT system securuty, and following all the possible dangers that can occur with the technology changes [7], [8].

This concept is also supported by our curriculum. Via the three subjects in the first year: Computer Networks, Information Systems Security and Management Information Systems students become familiar with basic notions and acquire basic skills from the field of IT systems security.

With regard to that, different levels should be recognized at which risk assessment is being performed. The very assessment is a matter which should represent the culmination of student knowledge that is impossible to be achieved with only one assessment. Therefore, it is intended that via this project students exchange their solutions, 
foreseen dangers and possible consequences and concrete measures that are to be undertaken, as well as the resulting acceptable risk.

Work on this subject was an immense challenge to the teacher. It was necessary to introduce to students the topic that has not been sufficiently dealt with in Serbia because of which there is no adequate literature. Besides, the subject requires knowledge that students cannot achive without considerable practice. For that reason, in this material there have been used several papers (published by teachers) in which the method and way of risk assessment were presented through several examples. The students were obliged to read all the papers and write a presentation of one of them. In that way, the students become familiar with the topic and develop critical opinion through which they will show if and how well they adopted the new material.

The other task was the description of a concrete IS, separation into layers according to structure and significance of resources and, finally, elaborated risk assessment for one of the layers. Finished tasks and solution discussion were elements of multiple importance for the students, as well as for the teachers. It used to happen that the students foresaw some dangers that were rare, but specific for particular cases and that would probably be recognized in the future. Besides, some of the students assigned high marks to damages of relatively small or easily removable dangers. In mutual discussion they were able to balance dangers and consequences and foresee risks in a more realistic way.

This method of course (subject) creation supports the modul problem based learning (PBL) offering students an integrated set of different problems which solutions ask for collaboratively work. [4]

\section{CONCLUSIONS}

This paper has the purpose of paying one`s attention to a new approach of planning of curriculum and syllabus. What is inteded as a reccomendation and what is expected is that plans and programmes should offer students beside theoretical knowledge also practical and applicable knowledge. They have to result from the needs of the environment, and the basic quality is the fact that in that way the students will be ,at the forefront“ included into current economic and social problems.

The quality that is achieved by such a creation of the content of the subject is the consequence of an active participation of teachers in solving of the existing problems, which is the only way to provide the students with the possibility of entering the 21 st century properly.

\section{REFERENCES}

1. Akreditacija u visokom obrazovanju (2010). (Accreditation in higher education), (2010). Ministarstvo prosvete Republike Srbije.

2. Bridges, D., Back to the future: the higher education curriculum in the 21 st Century. Cambridge Journal of Education, Vol. 30, No. 1, 2000 pp.37-55

3. Fallows, S., Steven, C., (2000) Building employability skills into the higher education curriculum: a university-wide initiative, Education + Training, Vol. 42 Iss: 2, pp.75-83

4. Jonassen, D., Strobel, J., Beng Lee, C., (2006). Everyday Problem Solving in Engineering: Lessons for Engineering Educators. Journal of Engineering Education; Apr 2006; 95, 2; ProQuest Education Journals, pp. $139-151$

5. Lucic, L., (2013). COSO enterprise risk management, VIII International Conference Safety Engineering, Kopaonik, Serbia

6. Nikolic, B., Ruzic-Dimitrijevic, L., Lovrekovic, Z., (Eds), (2013). Vodič za studente Informacionih tehnologija (Guide for students of Information technologies), VTS, Novi Sad, Serbia

7. NIST Special Publication 800-16: Information Technology Security Training Requirements: A Role-and Performance-Based Model, (2003).

8. NIST Special Publication 800-50: Building an Information Technology Security Awareness and Training Program, (2003). 


\section{Issues in Information Systems}

Volume 14, Issue x, pp. 463-467, 2013

9. Rege Colet, N., Durand, N., 2004. Working on the Bologna Declaration: Promoting integrated curriculum development and fostering conceptual change, International Journal for Academic Development Vol. 9, No. 2, November 2004, pp. 167-179

10. Ronald Barnett,Kelly Coate, (2005). Engaging The Curriculum In Higher Education, McGraw-Hill

11. Ruzic-Dimitrijevic, L., (2013). Impact of information system safety on the business risk, VIII International Conference Safety Engineering, Kopaonik, Serbia

12. Schleyer, G., Stacey, N., Simpson, K., (2009). Integrating risk concepts into undergraduate engineering courses. Prepared by the Health and Safety Laboratory and the University of Liverpool for the Health and Safety Executive 